\title{
NILAI KEARIFAN LOKAL BALI PADA KARYAWAN HOTEL DI KABUPATEN BADUNG
}

\author{
Made Arya Astina ${ }^{1}$, Komang Shanty Muni Parwati ${ }^{2}$ \\ Institut Pariwisata Dan Bisnis Internasional ${ }^{1,2}$ \\ arya.astinamade@gmail.com
}

\begin{abstract}
ABSTRAK
Penelitian tentang sumber daya manusia pariwisata ini berjudul Nilai Kearifan Lokal Bali pada Karyawan Hotel di Kabupaten Badung. Penelitian ini merupakan penelitian kualitatif yang dilakukan di daerah tujuan wisata di Bali yaitu daerah Badung. Teknik pengumpulan data dilakukan dengan penyebaran angket, dan studi kepustakaan. Periode penelitian akan dilaksanakan pada bulan Juni 2020 Desember 2020. Adapun subjek penelitian yang ditentukan adalah sejumlah 100 karyawan hotel di Kabupaten Badung. Kabupaten Badung dipilih sebagai lokasi penelitian dengan beberapa pertimbangan: 1) Badung merupakan kabupaten yang paling pesat pertumbuhan pariwisatanya di Bali, 2) Pertumbuhan jumlah hotel di daerah ini relative pesat, 3) Budaya yang dimiliki karyawan hotel di Kabupaten Badung perlu dianalisis untuk pengembangan produk (pelayanan). Teori yang digunakan dalam penelitian ini adalah teori nilai budaya dari Hofstede. Angket (kuesioner) yang digunakan merujuk kepada VSM (Value Survey Mudule) yang dikembangkan oleh Hofstede. Mengingat provinsi Bali mengandalkan sektor pariwisata untuk penghasilan utama daerahnya, maka penelitian ini penting dilakukan karena sumber daya manusia merupakan komponen yang penting dalam sebuah pelayanan. Penelitian ini menghasilkan beberapa informasi tentang nilai kearifan lokal pada karyawan hotel di Kabupaten Badung.
\end{abstract}

Kata kunci: Nilai Kearifan Lokal, Karyawan Hotel, Nilai Budaya

\section{ABSTRACT}

This research on tourism human resources is entitled The Value of Balinese Local Wisdom to Hotel Employees in Badung Regency. This research is a quantitative research conducted in a tourist destination in Badung, Bali. Data collection techniques were carried out by distributing questionnaires and literature studies. The research period will be carried out in June 2020 - December 2020. The research subjects determined are 100 hotel employees in Badung Regency. Badung Regency was chosen as the research location with several considerations: 1) Badung is the district with the fastest tourism growth in Bali, 2) The growth in the number of hotels in this area is relatively rapid, 3) The culture of hotel employees in Badung Regency needs to be analyzed for product development ( service). The 
theory used in this study is the theory of cultural values from Hofstede. The questionnaire used refers to the VSM (Value Survey Module) developed by Hofstede. Considering that the province of Bali relies on the tourism sector for its main regional income, this research is important because human resources are an important component in a service. This study produces some information about the value of local wisdom on hotel employees in Badung Regency.

Keywords: Value of Local Wisdom, Hotel Employees, Cultural Values

\section{PENDAHULUAN}

Pulau Bali terkenal sebagai salah satu destinasi wisata terpopuler di dunia. Pesona keindahan yang terpancar dari pulau yang sering disebut sebagai "surga pariwisata" ini di karena letak geografisnya, keunikan budayanya, dan kondisi sosialnya di mana mayoritas penduduknya beragama Hindu sementara secara nasional justru pemeluk Hindu menjadi minoritas (Picard, 1992). Bali juga menawarkan berbagai pilihan dan fasilitas penunjang kegiatan leisure bagi wisatawan yang berkunjung. Berbagai pesona siap memanjakan mata dapat dinikmati di pulau yang menjadi ikon wisata bertaraf internasional ini. Keindahan pantainya, hamparan sawah, dan kekhasan budaya masyarakat setempat menjadi pendukung berkembangnya industri hospitality

Perkembangan pariwisata Bali dari tahun ke tahun sangat dipengaruhi oleh berbagai faktor. Budaya menjadi faktor penting bagi wisatawan memilih Bali sebagai destinasi wisata pilihan. Terkenal dengan keragaman budaya yang dimiliki oleh masyarakatnya, konsep pariwisata Bali disebut juga sebagai pariwisata berbasis budaya atau sering disebut Pariwisata Budaya Bali. Pernyataan ini sejalan dengan undang-undang no. 2 tahun 2012 tentang Kepariwisataan Pariwisata Budaya yang dikembangkan di Bali dan diatur dalam Peraturan Daerah Provinsi.Adat, seni, dan budaya Bali merupakan sumber-sumber penghasil ekonomi dalam kegiatan industri hospitality. Dalam kegiatan dasar industri ini, tersirat satu cita-cita akan adanya hubungan timbal-balik yang baik dan positif antara pariwisata dan kebudayaan. Hubungan ini diharapkan mampu mendukung berbagai aktivitas sektor-sektor pariwisata agar beroperasi dengan maksimal.

Tentunya, selain hal-hal tersebut, kita tidak bisa mengesampingkan peranan para pelaku pariwisata di Bali dalam melakukan promosi. Mereka melakukan promosi baik secara offline dan online dengan berbasis teknologi informasi sehingga minat wisatawan untuk berkunjung diharapkan selalu tinggi. Teknologi informasi berperan sangat besar dalam perkembangan masa depan pariwisata budaya Bali.

Industri pariwisata Bali secara umum tumbuh secara positif dari tahun ke tahun. Jumlah sarana pendukung pariwisata di daerah ini terus berkembang, dengan kualitas yang juga semakin baik. Hotel sebagai salah satu usaha pariwisata di sektor penyedia akomodasi jumlahnya terus bertambah mengikuti jumlah kunjungan wisatawan yang datang berlibur. Dari data statistik dapat dilihat bahwa persentase 
kunjungan wisatawan mancanegara ke Pulau Bali sebagai daerah tujuan wisata utama di Indonesia terus mengalami peningkatan.

TABEL 1. PERSENTASE PENINGKATAN KUNJUNGAN WISATAWAN ASING KE BALI

\begin{tabular}{|l|l|lr|l|lr|lr|ll|}
\hline & Tahun & 014 & & 015 & 016 & 2 & 017 & 2 & 018 & 2 \\
\hline & Persentase & $4.89 \%$ & & $.24 \%$ & $3.14 \%$ & & $5.62 \%$ & $.54 \%$ & 6 \\
\hline
\end{tabular}

Sumber: BPS Provinsi Bali, (2019)

Perkembangan industri pariwisata selama beberapa dekade di Provinsi Bali tentunya tidak terlepas dari peran besar para pelaku pariwisatanya. Seperti yang disampaikan oleh Evans, Campbell, \& Stonehouse (2003) bahwa sumber daya manusia merupakan salah satu faktor yang berperan penting dalam memajukan sektor pariwisata. Sumber daya manusia di sektor pariwisata merupakan faktor kunci. Manusia (people) merupakan sumber daya yang sangat penting dalam sebagian besar organisasi, khususnya di organisasi berbasis jasa (service-based organization). Sumber daya manusia berperan sebagai faktor inti dalam mewujudkan keberhasilan kinerja sebuah organisasi.

Provinsi Bali memiliki Kabupaten Badung sebagai daerah tujuan wisata yang sudah sangat dikenal oleh wisatawan asing dan domestik. Potensi wisata di Desa Kabupaten Badung memberikan dukungan yang cukup besar terhadap kegiatan industri pariwisata secara umum di Bali. Hal ini karena beberapa tempat di Kabupaten Badung sudah menjadi destinasi wisata yang ikonik dan wajib dikunjungi, seperti Canggu, Seseh, Plaga. Berbagai aktivitas yang dilakukan tempat wisata tersebut menjadikan kawasan Kabupaten Badung terus berkembang dan menawarkan berbagai kesempatan bagi para pekerja dan stakeholder dari berbagai sektor pendukung industri pariwisata.

Kabupaten Badung juga terkenal sebagai pusat kesenian dan budaya Bali. Kawasan pariwisata Kabupaten Badung secara geografis masuk dalam Pemerintahan Kabupaten Badung. Kabupaten yang memiliki usaha akomodasi, restoran, atraksi paling banyak dan menjadi kabupaten paling besar berkontribusi secara ekonomi.

Perkembangan industri pariwisata di daerah ini diikuti pula dengan perkembangan jumlah sarana akomodasi dan sarana penunjang pariwisata lainnya. Dari tahun ke tahun, jumlah pekerja pada sektor pariwisata di daerah Kabupaten Badung terus bertambah. Mereka datang dari berbagai kabupaten di Bali, bahkan dari berbagai provinsi yang ada di Indonesia. Mereka menetap dan berbaur dengan masyarakat lokal, (misalnya di Kabupaten Badung, Bali) mencari nafkah dan turut berkontribusi di industri pariwisata.

Mengingat pentingnya peran sumber daya manusia pada sektor pariwisata, khususnya pada subsektor perhotelan, penelitian ini menganalisis nilai kearifan lokal Bali di antara hotel berbintang di daerah Kabupaten Badung. Dasar dari penelitian ini adalah penelitian Hofstede (2010) yang meneliti tentang nilai budaya di suatu daerah di Brazil. Terinspirasi dari riset Hofstede et al. tahun 2010 tersebut, 
penelitian ini juga ingin mengetahui bagaimana fenomena nilai kearifan lokal di Bali, khususnya di daerah Kabupaten Badung. Identifikasi nilai kearifan lokal Bali ini diharapkan akan memberikan kontribusi pemikiran dalam pengembangan sumber daya manusia pada sub sektor perhotelan di Bali pada umumnya, dan Kabupaten Badung pada khususnya.

\section{METODE PENELITIAN}

Penelitian ini dilaksanakan di daerah Kabupaten Badung. Periode penelitian akan dilaksanakan pada bulan Juni 2020-Agustus 2020. Subjek penelitian yang ditentukan adalah hotel berbintang di Kabupaten Badung. Adapun lokasi penelitian dipilih dengan pertimbangan destinasi wisata Kabupaten Badung yang merupakan salah satu daerah destinasi utama wisata yang berkembang relatif cepat. Tenaga kerja pariwisata, khususnya pada subsektor perhotelan, di daerah ini jumlahnya cukup banyak. Budaya yang dimiliki hotel berbintang berbintang di daerah Kabupaten Badung perlu dianalisis untuk pengembangan produk (pelayanan).

Dalam penelitian ini, teknik pengumpulan data yang juga digunakan adalah kuesioner (angket). Kuesioner digunakan untuk pengumpulan data dengan cara memberi seperangkat pertanyaan atau pernyataan tertulis kepada responden untuk jawabnya. Penentuan informan dalam penelitian ini dilakukan secara purposive, yaitu informan ditentukan berdasarkan ciri-ciri dan sifat tertentu yang dipandang mempunyai keterkaitan dan disesuaikan dengan tujuan dalam penelitian. Menurut Creswell (2015), purposive sampling berarti peneliti memilih individu dan tempat untuk diteliti karena mereka dapat secara spesifik memberi pemahaman tentang problem riset dan fenomena dalam studi tersebut.

Dalam penelitian ini digunakan kuesioner yang telah dikembangkan oleh Hofstede dengan menggunakan Skala Likert. Terdapat 34 pertanyaan untuk mengukur Jarak kekuasaan (Power Distance), Individualism vs. Kolektivitas, Maskulinitas vs. Feminitas, Uncertainty Avoidance, Orientasi jangka panjang vs. Orientasi jangka pendek, dan Pengikutsertaan (indulgence) vs. Pengekangan (restrain). Teknik analisis yang digunakan dalam menghitung skor dimensi budaya menggunakan VSM (value survey module) yang dikembangkan oleh Hofstede.

\section{HASIL DAN PEMBAHASAN}

Penelitian ini dilakukan di Kabupaten Badung, Provinsi Bali. Sebagai destinasi wisata Kabupaten Badung lebih dulu terkenal dengan destinasi wisata Kuta, daerah BTDC Nusa Dua Jimbaran, Plaga, Canggu, dan Seseh. Adapun hotelhotel yang karyawannya dijadikan responden di daerah ini adalah:

\section{TABEL 2. PROFIL RESPONDEN}

\begin{tabular}{|l|l|l|}
\hline \multirow{2}{*}{ Daerah } & \multicolumn{1}{|c|}{ Nama Hotel } & $\begin{array}{c}\text { Jumlah } \\
\text { Responden } \\
\text { (orang) }\end{array}$ \\
\hline Kabupaten Badung & Hotel Neo+ Kuta, Legian & 18 \\
\cline { 2 - 3 } & Permata Kuta Hotel & 20 \\
\hline
\end{tabular}




\begin{tabular}{|l|l|l|}
\hline & Favehotel Kuta Kartika Plaza & 25 \\
\cline { 2 - 3 } & Grand Mega Resort \& Spa & 22 \\
\cline { 2 - 3 } & Grandmas Plus Hotel Airport & 10 \\
\cline { 2 - 3 } & Max One Hotel, Jimbaran & 20 \\
\cline { 2 - 3 } & Kutabex, Jimbaran & 20 \\
\cline { 2 - 3 } & Total & $\mathbf{1 3 5}$ \\
\hline
\end{tabular}

\subsubsection{Profil Responden}

Responden dari penelitian ini adalah hotel berbintang yang diambil dari berbagai departemen pada 7 hotel yang berbeda.

Adapun profil dari responden adalah sebagai berikut:

\section{TABEL 3. PROFIL RESPONDEN}

\begin{tabular}{|c|c|c|c|}
\hline No & \multicolumn{2}{|l|}{ Profil Responden } & Seminyak \\
\hline 1 & \multicolumn{2}{|c|}{ Jumlah Responden } & 135 \\
\hline \multirow[t]{2}{*}{2} & \multirow[t]{2}{*}{ Jenis Kelamin } & Laki-laki & 99 \\
\hline & & Perempuan & 36 \\
\hline \multirow[t]{6}{*}{3} & \multirow[t]{6}{*}{ Rentangan Usia } & $<20$ tahun & 0 \\
\hline & & 20-24 tahun & 25 \\
\hline & & 25-29 tahun & 40 \\
\hline & & 30-34 tahun & 32 \\
\hline & & 35-39 tahun & 35 \\
\hline & & 40-49 tahun & 3 \\
\hline
\end{tabular}

\subsubsection{Penghitungan Skor Nilai Budaya Hotel Berbintang di Kabupaten Badung}

Penghitungan skor nilai budaya hotel berbintang di Kabupaten Badung dilakukan dengan menggunakan rumus penghitungan indeks Value Survey Mudule (VSM) 2013 yang ditetapkan oleh Hofstede. Adapun rumus yang digunakan untuk menghitung indeks dari 4 (empat) dimensi budaya adalah sebagai berikut:

TABEL 4. RUMUS PENGHITUNGAN INDEKS

\begin{tabular}{|l|l|l|}
\hline No & Dimensi Budaya & Rumus Penghitungan Indeks \\
\hline 1 & Power Distance Index (PDI) & $35(\mathrm{~m} 07-\mathrm{m} 02)+25(\mathrm{~m} 20-\mathrm{m} 23)+\mathrm{C}(\mathrm{pd})$ \\
\hline 2 & Individualism vs Collectivism (IDV) & $35(\mathrm{~m} 04-\mathrm{m} 01)+35(\mathrm{~m} 09-\mathrm{m} 06)+\mathrm{C}(\mathrm{ic})$ \\
\hline 3 & Mascullinity vs Femininity (MAS) & $35(\mathrm{~m} 05-\mathrm{m} 03)+35(\mathrm{~m} 08-\mathrm{m} 10)+\mathrm{C}(\mathrm{mf})$ \\
\hline 4 & Uncertainty Avoidance (UAI) & $40(\mathrm{~m} 18-\mathrm{m} 15)+25(\mathrm{~m} 21-\mathrm{m} 24)+\mathrm{C}(\mathrm{ua})$ \\
\hline
\end{tabular}


Adapun hasil dari penghitungan indeks masing-masing dimensi budaya dikelompokan sebagai berikut:

TABEL 5. SKALA DIMENSI BUDAYA HOFSTEDE

\begin{tabular}{|l|l|l|l|}
\hline No & Dimensi & Rentangan Skor & Hasil \\
\hline 1 & \multirow{2}{*}{ PDI } & $0-50$ & Small \\
\cline { 3 - 4 } & & $50-110$ & Large \\
\hline 2 & \multirow{2}{*}{ IDV } & $5-50$ & Collectivism \\
\cline { 3 - 4 } & & $50-95$ & Individualism \\
\hline 3 & MAS & $5-50$ & Feminism \\
\cline { 3 - 4 } & & $50-95$ & Maskuline \\
\hline 4 & UAI & $5-60$ & Weak \\
\cline { 3 - 4 } & & $60-115$ & Strong \\
\hline
\end{tabular}

Berdasarkan rumus penghitungan indeks dan rentangan skor yang telah ditetapkan, maka hasil perhitungan dimensi budaya hotel berbintang di Kabupaten Badung sebagai berikut:

TABEL 6. REKAPITULASI PENILAIAN JAWABAN HOTEL BERBINTANG

\begin{tabular}{|c|c|c|c|c|c|c|c|}
\hline \multirow{2}{*}{ Daftar Pertanyaan } & \multicolumn{5}{|c|}{ Skala Penilaian Jabatan } & \multirow{2}{*}{ Total } & \multirow{2}{*}{ Rata-rata } \\
\hline & 1 & 2 & 3 & 4 & 5 & & \\
\hline Pertanyaan No. 1 & 93 & 71 & 76 & 0 & 0 & 463 & 10,2889 \\
\hline Pertanyaan No. 2 & 106 & 70 & 53 & 11 & 0 & 449 & 9,97778 \\
\hline Pertanyaan No. 3 & 119 & 92 & 28 & 1 & 0 & 391 & 8,68889 \\
\hline Pertanyaan No. 4 & 103 & 30 & 90 & 15 & 2 & 503 & 11,1778 \\
\hline Pertanyaan No. 5 & 120 & 101 & 19 & 0 & 0 & 379 & 8,42222 \\
\hline Pertanyaan No. 6 & 107 & 101 & 31 & 0 & 1 & 407 & 9,04444 \\
\hline Pertanyaan No. 7 & 93 & 92 & 49 & 6 & 0 & 448 & 9,95556 \\
\hline Pertanyaan No. 8 & 106 & 102 & 32 & 0 & 0 & 406 & 9,02222 \\
\hline Pertanyaan No. 9 & 144 & 69 & 25 & 2 & 0 & 365 & 8,11111 \\
\hline Pertanyaan No. 10 & 109 & 99 & 30 & 1 & 1 & 406 & 9,02222 \\
\hline Pertanyaan No. 11 & 78 & 65 & 88 & 9 & 0 & 508 & 11,2889 \\
\hline Pertanyaan No. 12 & 121 & 32 & 81 & 5 & 1 & 453 & 10,0667 \\
\hline Pertanyaan No. 13 & 16 & 88 & 123 & 5 & 8 & 621 & 13,8 \\
\hline Pertanyaan No. 14 & 99 & 98 & 33 & 3 & 7 & 441 & 9,8 \\
\hline Pertanyaan No. 15 & 0 & 69 & 38 & 122 & 11 & 795 & 17,6667 \\
\hline Pertanyaan No. 16 & 112 & 104 & 22 & 2 & 0 & 394 & 8,75556 \\
\hline Pertanyaan No. 17 & 38 & 116 & 56 & 30 & 0 & 558 & 12,4 \\
\hline Pertanyaan No. 18 & 27 & 35 & 16 & 63 & 99 & 892 & 19,8222 \\
\hline Pertanyaan No. 19 & 118 & 18 & 72 & 9 & 23 & 521 & 11,5778 \\
\hline Pertanyaan No. 20 & 5 & 102 & 21 & 104 & 8 & 728 & 16,1778 \\
\hline Pertanyaan No. 21 & 34 & 83 & 26 & 93 & 4 & 670 & 14,8889 \\
\hline Pertanyaan No. 22 & 30 & 84 & 0 & 41 & 85 & 787 & 17,4889 \\
\hline Pertanyaan No. 23 & 8 & 86 & 29 & 91 & 26 & 761 & 16,9111 \\
\hline Pertanyaan No. 24 & 3 & 13 & 104 & 115 & 5 & 826 & 18,3556 \\
\hline
\end{tabular}


Hotel berbintang di daerah ini terbukti masih memegang kearifan lokal yang disebut dengan "menyama braya". Konsep "menyama braya" merupakan konsep hidup bermasyarakat di Bali yang bersumber dari sistem nilai budaya dan adat istiadat masyarakat setempat untuk dapat hidup rukun. Nilai kearifan lokal "menyama braya" mengandung makna kebersamaan, persaudaraan dan pengakuan sosial bahwa kita adalah bersaudara.

Terkait dengan budaya demokrasi, hotel berbintang di daerah ini menerapkan nilai-nilai kearifan lokal Bali, beberapa diantaranya: tat twam asi (toleransi tanpa menonjolkan perbedaan); paras paros (saling memberi dan menerima pendapat orang lain); merakpak danyuh atau perbedaan pendapat tidak menghilangkan persahabatan.

Budaya yang terlihat pada hotel berbintang di daerah ini yang memiliki skor yang rendah untuk budaya (feminine) artinya mereka memiliki preferensi yang tinggi terhadap kualitas hidup dan perhatian pada individu lain (kehidupan sosial). Nilai masculinity yang rendah pada hotel berbintang di daerah ini menunjukan nilai budaya Bali dalam konsep Jengah (dorongan kuat dari diri sendiri untuk melakukan perubahan) tidak sepenuhnya dimiliki oleh hotel berbintang di Kabupaten Badung.

Hotel berbintang yang memiliki uncertainty avoidance yang rendah memiliki ciri sering melakukan inovasi dikarenakan bagi mereka sesuatu yang baru merupakan hal yang tidak ditakuti dan harus dilakukan.

\section{SIMPULAN}

1. Kabupaten Badung mempunyai budaya dengan tingkat collectivism yang cukup tinggi. Hal ini juga membuktikan bahwa hotel berbintang di daerah ini memiliki budaya kebersamaannya dan kekompakannya (collectivism). Wujudnya adalah karyawan di hotel berbintang yang bekerja terbukti masih memegang kearifan lokal yang disebut dengan "menyama braya".

2. Pekerja hotel menunjukan nilai jarak kekuasaan (power distance) yang rendah. Hal ini berarti hubungan antara atasan dan bawahan pada hotel berbintang di kabupaten Badung cukup dekat. Pimpinan hotel dihormati bukan semata-mata karena posisi mereka, namun karena gaya kepemimpinannya.

3. Pekerja hotel berbintang cenderung memiliki budaya Feminin, yang menunjukan bahwa karyawan hotel berbintang memiliki motivasinya timbul bukan karena ingin menjadi yang terbaik (masculinity), melainkan motivasi kerja menyukai apa yang sedang dilakukannya (feminine). Mereka bekerja bukan untuk berkompetisi.

4. Pekerja hotel menunjukkan tingkat uncertainty avoidance yang tergolong rendah. Skor ini menunjukan bahwa hotel berbintang di daerah ini tidak begitu takut terhadap sesuatu yang tidak pasti atau ambigu dan menyukai ideide serta konsep-konsep yang baru dan berbeda dari biasanya.

\section{DAFTAR PUSTAKA}

Abdi, U. R. (2008). Metodologi Penelitian Sosial dan Ekonomi: Teori dan Aplikasi. Alfabeta, Bandung, ISBN: 9789798433863. 
ARTINI, N. A. (2007). PERANAN DESA ADAT DALAM PENGELOLAAN KEPARIWISATAAN (STUDI KASUS DI DESA ADAT SEMINYAK, KECAMATAN KUTA, KABUPATEN BADUNG). SOCA: Socioeconomics of Agriculture and Agribusiness, 7.

Astiti, Putra Tjok Istri. 2010. Desa Adat Menggugat Dan Digugat. Denpasar: Udayana University Press.

Bearden, W. O. (2006). Multidimensional versus unidimensional measures in assessing national culture values: The Hofstede VSM 94 example. Journal of Business Research, 59.

Benny H. Hoed. 2008. Semiotik dan Dinamika Sosial Budaya. Depok: Fakultas Ilmu Pengetahuan Budaya (FIB).

BERRY, J. W. (2019). Culture and cognition: Readings in cross-cultural psychology.

Berry, John W., Segall, Marshall H., 7 \& Kagitcibasi, Cigdem. 1997. Handbook of Cross Cultural Psychology: Social Behavior and Applications $\left(2^{\text {nd }}\right.$ Ed). USA: Allyn \& Bacon.

Brata, Y. R. (2020). DINAMIKA BUDAYA DAN SOSIAL DALAM PERADABAN MASYARAKAT SUNDA DILIHAT DARI PERSPEKTIF SEJARAH. Jurnal Artefak, 7.

Chaudhary, N. (2018). Cross-Cultural Psychology as a Solution to Global Inequality: Optimism, Overconfidence, or Naiveté?: A commentary on "The Positive Role of Culture: What Cross-Cultural Psychology Has to Offer to Developmental Aid Effectiveness Research" by Symen A. Brouwe. Journal of Cross-Cultural Psychology, 49.

Creswell, J. W. (1990). Penelitian Kualitatif \& Desain Riset. Mycological Research, 94.

Creswell, J. W. (2015). Penelitian Kualitatif dan Desain Riset (memilih diantara lima pendekatan). Penelitian Kualitatif.

Englund, R. (1992). Cross-cultural management communication by Richard Mead. New York. Journal of Product Innovation Management, 9.

Evans, N. C. (2012). Strategic management for travel and tourism.

Gorda, I Gusti Ngurah. 1997. Metodologi Penelitian Sosial Ekonomi. Denpasar: Widya Kriya Gematama.

Hofstede, G. (1080). Culture and Organizations. International Studies of Management \& Organization, 10.

Hofstede, G. G. (2010). Comparing regional cultures within a country: Lessons from Brazil. Journal of Cross-Cultural Psychology, 41.

https://bali.bps.go.id/statictable/2018/02/09/21/jumlah-wisatawan-asing-ke-balimenurut-bulan-1982-2019.html diakses pada tanggal (5 Juni 2020)

Huang, S. (. (2019). Relationships between Hofstede's cultural dimensions and tourist satisfaction: A cross-country cross-sample examination. Tourism Management, 72.

Kartika, N. G. (2019). Hubungan Timbal Balik Antar Desa Adat dan Pariwisata. PARIWISATA BUDAYA: JURNAL ILMIAH AGAMA DAN BUDAYA, 4.

Kieser, A. (1994). Cultures and Organizations. Software of the Mind. Organization Studies, 15. 
Mintu, A. T. (2004). Geert Hofstede CULTURES AND ORGANIZATIONS SOFTWARE OF THE MIND. Crossroads, 23.

Mead, Richard. 1990. Cross Cultural Management Communication. England: John Wiley \& Sons Ltd.

Nandi, N. (2016). PARIWISATA DAN PENGEMBANGAN SUMBERDAYA MANUSIA. Jurnal Geografi Gea, 8.

Rohaeti, E. E. (2019). PROGRAM PENDAMPINGAN BERBASIS KEARIFAN LOKAL DESA ADAT SENARU DALAM MENINGKATKAN MOTIVASI BELAJAR ANAK-ANAK DESA ADAT SENARU. Abdimas Siliwangi, 2.

Sydorchuk, O. K. (2019). Strategic management of a travel company in the conditions of introduction of modern information technologies. Academy of Strategic Management Journal, 18. 